\title{
Secondary Traumatic Stress: Prevalence and Symptomology Amongst Detective Officers Investigating Child Protection Cases
}

\author{
Alison D. MacEachern ${ }^{1} \cdot$ Ashley A. Dennis ${ }^{2,3} \cdot$ Sharon Jackson $^{4} \cdot$ Divya Jindal-Snape $^{1,5}$
}

Published online: 3 June 2018

(C) The Author(s) 2018

\begin{abstract}
It has been increasingly recognised that individuals exposed to the trauma of others within their professional roles can be affected by secondary traumatic stress (STS). Despite this recognition, there is a dearth of literature examining the prevalence of secondary traumatic stress amongst police officers in the UK. This study aims to meet this gap. Sixty-three Detective Officers from Family Protection Units (FPU(s)), primarily engaged in child protection/abuse investigations, self-reported their experiences and symptoms associated with STS through a questionnaire. Findings indicate that over half of the respondents experienced STS symptoms with $11 \%$ reporting levels of symptoms that were in the high or severe range. This study is significant in that it provides empirical evidence of issues that have so far been little documented in the UK and considers the implications for policing policy and practice in terms of the health and well-being of serving police officers.
\end{abstract}

Keywords Child protection $\cdot$ Secondary traumatic stress $\cdot$ Police $\cdot$ Well-being

\section{Introduction}

Exposure to trauma (e.g. terrorism, natural disasters, child abuse) can impact on the health and well-being of individuals (MacEachern et al. 2011; Palm et al. 2004). A body of literature considers the ways in which police officers can be affected through exposure to traumatic situations. Often, this work examines the incidence or prevalence of post-traumatic stress disorder (PTSD) and other traumatic symptomatology amongst police officers in various contexts such as exposure to death, threat of death, homicide or 'body handling' (Alexander and Wells 1991; Sewell 1994; Sugimoto and Oltjenbruns 2001) and victim work (Martin et al. 1986). The definition and criteria for PTSD have been debated in the

Divya Jindal-Snape

d.jindalsnape@dundee.ac.uk

1 Research Centre for Transformative Change: Educational and Life Transitions (TCELT), University of Dundee, Dundee, UK

2 Billings Clinic, Billings, MT, USA

3 Centre for Medical Education, University of Dundee, Dundee, UK

4 Department of Psychology, Social Work and Allied Health Sciences, Glasgow Caledonia University, Glasgow, UK

5 School of Education and Social Work, University of Dundee, Nethergate, Dundee DD1 4HN, UK literature and have changed over time (Levin et al. 2014). Levin et al. (2014, pp. 146) suggest that the core criteria that have maintained consistency are 'exposure to a traumatic stressor [...], re-experiencing the trauma, numbing and avoidance $[\ldots]$, and increased arousal and vigilance'.

For the most part, the empirical focus of such trauma research in police officers has been on the individuals who have been directly exposed to trauma with the aim to develop treatment associated with PTSD (Palm et al. 2004). There is also a notable research literature that has sought to understand a wide range of PTSD-associated phenomena amongst police officers such as the influence of gender, ethnicity and personality traits in the development of PTSD (Hodgins et al. 2001; Lilly et al. 2009; Pole et al. 2001). For instance, literature suggests that rates of PTSD (e.g. current rates, lifetime prevalence) are generally higher in women (see Tolin and Foa 2006 for a review). However, when exploring PTSD and gender in police studies, there is less consistency. Some studies report gender differences in the police (Bowler et al. 2010), whilst others have found no gender differences between police women and men (Andrew et al. 2008; Ellrich and Baier 2015; Pole et al. 2001). Furthermore, in comparing police women to female civilians, police women have been shown to have less severe PTSD symptomology (Lilly et al. 2009).

Although there has been a significant body of research exploring police officers' direct exposure to trauma, MacEachern et al. (2011) highlight that there is a dearth of research investigating the effect upon individuals indirectly 
exposed to trauma. These are individuals who do not directly experience a traumatic event but are exposed to it indirectly, for instance through the experiences of others. According to Herman (1992), professionals employed in the field of psychosocial services are very likely to encounter persons who have experienced one or more traumatic events. These range from medical, mental health and other healthcare workers to emergency personnel (including police officers, fire fighters and paramedics), social workers and media professionals (Palm et al. 2004). Psychosocial service providers often must share the emotional burden of the trauma, bearing witness to damaging or cruel circumstances that individuals have experienced and acknowledge the existence of terrible and traumatic events in the world (Herman 1992). Note that the emotional impact the caregiver experiences as a result of the terror and anguish can produce a unique set of symptoms such as helplessness, rage, anger, depression, isolation, paranoia and hypervigilance. McCann and Pearlman (1990) and Figley (1995) further assert that as a direct consequence of the process, service providers are repeatedly encountering traumatic events through vivid and detailed descriptions of what the survivor has directly experienced, which may result in the emergence of secondary traumatic stress symptoms.

This phenomenon has been variously described and defined within the literature as 'secondary traumatic stress' (STS; Figley 1995), 'secondary traumatic stress disorder' (STSD; Munroe et al. 1995), 'vicarious traumatisation' (McCann and Pearlman 1990), 'compassion fatigue' and so forth (see for example, Joinson 1992). Importantly, the most recent version of the DSM (Diagnostic and Statistical Manual of Mental Disorders), DSM-V, has expanded its PTSD criteria, to include not only direct experience of a traumatic event but also indirect exposure (e.g. 'experiencing repeated or extreme exposure to aversive details of the traumatic events') such as police officers investigating child abuse (Levin et al. 2014, pp. 147). There is considerable controversy surrounding the conceptual difference between these various constructs (Jenkins and Baird 2002) and a lack of consistency within the literature regarding how these conditions may differ or converge (Leinwber and Rowe 2008; Najjar et al. 2009).

For the purposes of this study, we used the concept of 'secondary traumatic stress' defined by Bride and Kintzle (2011, pp. 22) as:

'STS refers to the occurrence of posttraumatic stress symptoms following indirect exposure to traumatic events. The indirect exposure typically occurs via a close personal or professional relationship with one or more traumatized persons who recount, often repetitively, the traumatic experience'

Thus, STS is considered to be the manifestation of PTSD symptoms amongst persons who are connected to the traumatic experiences of others (Collins and Long 2003).
Although there is literature that discusses the possibility that police officers may be affected by STS (e.g. Brown et al. 2010), there is limited empirical evidence which aims to understand or measure STS in the context of police officers. In part, the lack of work around STS amongst police officers may be attributable to the fact that STS has only recently begun to be studied as a phenomenon in its own right (see MacEachern et al. 2011 for a full review). However, one area of law enforcement investigation that has received attention in recent years in regard to STS has been in the context of internet child exploitation (Bourke and Craun 2014a; Bourke and Craun 2014b; Brady 2016; Perez et al. 2010). Perez et al. (2010) explored STS in law enforcement personnel in the USA who investigated child pornography cases. They found that a large proportion of the personnel had symptoms of STS with average scores on the Secondary Traumatic Stress Scale (STSS; Bride et al. 2004) indicating moderate STS. Their study also highlighted that the amount of time the participants specified they had worked with disturbing material was also positively associated with symptoms of STS. Bourke and Craun (2014a) also explored STS in over 600 personnel across the USA who investigate internet child exploitation. They found that the majority of participants experienced mild severity or lower of STS symptoms using the STSS. However, $15 \%$ of participants were experiencing levels of symptoms classified in the severe range. They also explored coping mechanisms in relation to STS scores and found that social support, particularly supervisory support, was associated with lower STS scores. On the other hand, denial was the only coping mechanism that was associated with higher STS scores. Finally, they found that being male was predictive of lower STS scores. However, a key critique of their study was that $73 \%$ of participants were male.

Craun et al. (2014) explored scores of STS in a group of law enforcement personnel that were involved in sex offence investigations as well as a broader group of deputies also involved in the Deputy US Marshals over a 3-year period of time. On average, this group of law enforcement personnel had lower scores of STS than those described in Perez et al. (2010) and Bourke and Craun (2014a). Whilst the majority of participants had scores in the mild severity or lower symptoms of STS (73.15), only $6.7 \%$ of individuals reported symptoms in the severe range. In general, they found that most individual's STS scores remained stable over time. Supervisory support and avoidance of a denial style of coping were important longitudinally. Low physical activity was also associated with great risk of STS and an increase in the use of alcohol or tobacco aligned with large increases in STS scores. Finally, gender was not predictive of STS scores.

The majority of studies exploring STS in law enforcement personnel focus on the US context. Only one study so far has explored the UK context. Bourke and Craun (2014b) compared UK and US law enforcement personnel working in child 
exploitation. The UK sample had lower STS scores as compared to the US sample. For example, in the US sample, $15.3 \%$ of personnel were in the severe category of STS on the STSS scale as compared to $10.4 \%$ of individuals in the UK sample. Furthermore, the UK sample had a larger proportion $(36.9 \%)$ of individuals in the low/no STS category as compared the US sample (26.4\%). This study suggests that there are differences between the USA and UK in relation to STS scores, and therefore, more research is needed in the UK context to enable further comparisons to be made in the literature.

This study therefore has several key aims. First, it aims to explore the level and experience of STS in law enforcement personnel in the UK to provide further understanding of the UK context and enable comparisons with other populations. Second, it aims to explore gender differences. To address these aims, we have developed two research questions:

1) What is the experience of STS in detective officers working in the Family Protection Unit (FPU)?

2) Are there gender differences in STS levels amongst detective officers?

\section{Study Methods and Analysis}

\section{Study Design}

The study was conducted with a Police Force in the UK. A self-completion questionnaire was utilised, which contained both qualitative and quantitative components.

\section{Sampling and Recruitment}

After approval from the Assistant Chief Constable Crime (Operations) and ethical approval from the University Research Ethics Committee, an independent senior HR officer contacted all 100 police officers who were at that time conducting or were about to commence the role of FPU officer with the Family Protection Unit. FPUs are staffed primarily by practitioners (Detective Constables), with first-line management/supervisory responsibility being over seen by Detective Sergeants. At the time of the study, officers in the FPU dealt with a range of additional types of investigations such as sexual assault, cot death and missing persons. Detectives were involved in both noting witness statements from victims/survivors and in interviewing the suspect/accused. It was considered imperative to explore views from these various stakeholders working within the FPUs.

Professional codes of ethical practice were adhered to in respect to participant confidentiality and anonymity, informed consent, data collection/ storage, analysis and dissemination.
Because of the sensitative nature of the study, particular care was taken to ensure participants had detailed information about the nature of the study and issues of data protection. Invited respondents were sent an initial covering letter outlining the nature of the study directly from Force Head Quarters. Afterwards, Force Head Quarters also sent an information sheet, consent letter and questionnaire along with a return address envelope addressed to divisional FPU personnel. The information sheet provided a detailed overview of and instructions for the study in addition to the contact details of the researcher (DM) if there were any questions or concerns. DM is an insider researcher who has worked directly in the Force as a trainer/lecturer in the area of FPU. Given the nature of the issues being explored, mechanisms were identified and implemented to ensure that all participants could access information and sources of support if and when necessary.

Sixty-three police officers ( 34 female and 29 male) participated in the study. All of the respondents were 26 years of age or over. The majority of participants were full-time FPU detectives (62\%); however, individuals in other roles were also identified (see Table 1). One individual did not indicate their current role. The range of service of respondents (number of years employed as police officers) was distributed over 4 30 years (see Table 1 for full information).

\section{Data Collection}

The questionnaire contained two broad components. The first component was the Secondary Traumatic Stress Scale (STSS) which measured STS. This STSS was devised by Bride et al. (2004) to measure work-related STS in social workers. The scale is composed of three subscales (intrusion, e.g., 'I had disturbing dreams about my work with clients'; avoidance, e.g., 'I wanted to avoid working with some clients'; and arousal, e.g., 'I was easily annoyed') with each item on the STSS (Bride et al. 2004) corresponding to one of the 17 PTSD symptoms outlined in the DSME-IV-TR (APA, 2000). The STSS was tailored to suit a British-based research study involving a Police Force after discussion with Bride. Respondents were asked to indicate how frequently they experienced each of the 17 symptoms using a five-option Likerttype response format, ranging from 1 to $5(1=$ never, $5=$ most of the time). A score for each respondent was obtained by summing up the responses, giving a possible score of 17 $(17 \times 1=17)$ to $85(17 \times 5=85)$. A symptom was considered 'endorsed' by a respondent if 'occasionally', 'frequently' or 'most of the time' was indicated, i.e. ratings 3, 4 or 5.

The second component was a set of open questions to further explore participants' experiences and perspectives of working in the FPU, i.e. experiences with traumatised persons (clients/complainers/witnesses who may have experienced or witnessed various kinds of abuse). It also explored the personal experiences of working within the FPU including 
Table 1 Participant characteristics

\begin{tabular}{|c|c|c|c|}
\hline Characteristic & & Number $(\%)$ & Female/male \\
\hline \multirow[t]{2}{*}{ Gender } & Female & $34(54 \%)$ & - \\
\hline & Male & $29(46 \%)$ & - \\
\hline \multirow[t]{6}{*}{ Job role } & $\mathrm{FPU}-\mathrm{F}=23 / \mathrm{M}=16$ & $39(62 \%)$ & \\
\hline & Trainee detectives $-\mathrm{F}=5 / \mathrm{M}=4$ & $9(14 \%)$ & \\
\hline & Supervisors $-\mathrm{F}=1 / \mathrm{M}=6$ & $7(11 \%)$ & \\
\hline & DO general CID - $\mathrm{F}=2 / \mathrm{M}=2$ & $4(6 \%)$ & \\
\hline & Secondment $-\mathrm{F}=1 / \mathrm{M}=0$ & $1(2 \%)$ & \\
\hline & Another role $-\mathrm{F}=1 / \mathrm{M}=1$ & $2(3 \%)$ & \\
\hline \multirow[t]{3}{*}{ Years of police experience } & $4-7$ years & $12(9 \%)$ & $\mathrm{F}=6 / \mathrm{M}=6$ \\
\hline & $8-25$ years & $43(68 \%)$ & $\mathrm{F}=28 / \mathrm{M}=15$ \\
\hline & $26-30$ years & $8(13 \%)$ & $\mathrm{F}=0 / \mathrm{M}=8$ \\
\hline \multirow[t]{6}{*}{ Years in FPU post } & $0-6$ months & 8 & $\mathrm{~F}=6 / \mathrm{M}=2$ \\
\hline & 7 months -1 year & 16 & $\mathrm{~F}=5 / \mathrm{M}=11$ \\
\hline & $1-2$ years & 9 & $\mathrm{~F}=5 / \mathrm{M}=4$ \\
\hline & $2-3$ years & 16 & $\mathrm{~F}=8 / \mathrm{M}=8$ \\
\hline & $3-4$ years & 2 & $\mathrm{~F}=0 / \mathrm{M}=2$ \\
\hline & $4+$ years & 11 & $\mathrm{~F}=9 / \mathrm{M}=2$ \\
\hline \multirow[t]{2}{*}{ Dependent* } & Had dependent & $31(51 \%)$ & $\mathrm{F}=15 / \mathrm{M}=16$ \\
\hline & Did not have dependent & $30(49 \%)$ & $\mathrm{F}=19 / \mathrm{M}=11$ \\
\hline
\end{tabular}

Note: Numbers do not always add to 63 due to missing response. $*$ Dependents $=$ babies and children under school age; school age children and or disabled relative, people the officer is responsible for caring for in their own family

perspective on the psychosocial impact of FPU work, quality of life, health, support mechanisms and the extent to which negative psychosocial phenomena and emotions impact upon occupational performance. The construction of the questionnaire was informed by the theoretical and empirical literature on PTSD/STSS. The questionnaire was piloted with a small subsample of FPU police officers $(n=4)$ to strengthen validity along a range of dimensions (face, content and construct validity).

\section{Data Analysis}

The questionnaire collected both quantitative and qualitative data. The data collected required both statistical analysis and the development of common/recurring or new themes. Quantitative data were analysed using SPSS. Descriptive statistics including frequencies and summary statistics (means and standard deviations) were first obtained. Inferential statistical tests were then conducted using both parametric and nonparametric, chi-square tests and independent samples $t$ tests. The level of probability throughout the study was $p=0.05$. Qualitative data were extracted from the semi structured questionnaire and were subjected to a manual thematic analysis as espoused by Denscombe (2007) following five stages: data preparation, familiarity with the data, data interpretation (development of categories/themes and concepts), data verification, presenting the data. The research team were involved in a sample cross-check.

\section{Results}

\section{Exposure to Trauma}

In order to assess the extent to which police officers in the sample were exposed to the trauma of others, participants were asked to estimate the prevalence of trauma amongst clients/witness/complainer's with whom they had conducted investigations. Twelve (4 male, 8 female) participants considered the percentage of trauma in those they worked with to be over 70\%, 20 (12 male, 8 female) participants considered it to be between 51 and 70\%, 22 ( 9 male, 13 female) participants between 21 and $50 \%$ and 7 ( 2 male, 5 female) less than $20 \%$. Two male participants did not respond to this question. An independent sample $t$ test revealed no significant difference between males $(\mathrm{M}=5.88, \mathrm{SD}=2.39)$ and females $(\mathrm{M}=$ $5.20, \mathrm{SD}=2.91)$ in relation to the perception of the prevalence of client/witness/complainer trauma ( $\mathrm{t}(59)=.0983, p=.32$ (two tailed). These data suggest that although there was variance in the extent to which police officers consider themselves to be exposed to the trauma of others, the majority of participants considered themselves to be exposed to some degree.

\section{Level of Symptom Severity}

The means, standard deviations and ranges of score on the STS were calculated for all participants (see Table 2). When broken down by gender, there were no significant 
differences found between male (median =28) and female (median $=29$ ) participants in mean STS score using a Mann-Whitney $U(U=461, z-.442$, ns, $r=-.06)$. We also calculated mean scores for the intrusion, avoidance and arousal subscales (see Table 2). There were also no significant differences between male and females in scores across the subscales.

Half of respondents experienced little or no STS (see Table 3). Three respondents were found to be experiencing 'high' levels of STS whilst four respondents fell within the 'severe' category. Although there were no statistically significant differences between males and females in overall scores, it is interesting to note that only females in this study met the criteria for 'severe' STS. Crucially, these results indicate that over half of the respondents $(51 \%)$ were experiencing some symptoms associated with STS.

The 17 symptoms were categorised under intrusion symptoms, avoidance symptoms and arousal symptoms. Responses in relation to intrusion symptoms (symptoms 1-5) contained the least and most frequently experienced symptoms. The most frequently reported symptom was intrusive thoughts about victims, complainers and suspects with 10 male and 12 female respondents indicating that they thought about their work without intending to. A symptom was considered to be present for respondents indicating 'occasionally', frequently' or 'most of the time'. Endorsement of the seven avoidance symptoms (symptoms 6-12) was varied. Emotional numbing was the most frequently reported symptom in this subscale and across the full STS where 19 males and 23 females reported experiencing emotional numbing. No participants indicated that they avoided people, places or things serving as a reminder of work. Finally, we explored rates for endorsement of the remaining arousal symptoms (symptoms 1317). Hypervigilance was the most frequently reported symptom in this category and was the second highest across the scale (males, $N=13$; females, $N=20$ ).

\section{Experiences of Symptoms}

\section{Burnout}

Many participants discussed that their work was emotionally and physically draining and exhausting. In relation to this, many reported that they had experienced a loss of enthusiasm and sense of achievement in their work. Others reported feeling professionally inadequate because they felt 'tired', drained', 'exhausted' and 'stressed'. One participant wrote,

[I am] just tired and stressed which leads to slowness of mind and easy confusion when dealing with an incident that requires attention to detail, heavy limits (Respondent 48, female, 4-7 years' service, Aide to FPU)

\section{Sleeping Difficulties}

Respondents indicated that they sometimes experienced sleeping difficulties as a result of the work or that sleeping difficulties could be exacerbated. One respondent said,

I suffer from difficulty sleeping. I have always done, however, with my brain being so active in my current role, I find insomnia has been exacerbated and if I do not fall asleep quickly my thoughts often become that of current or past work. (Respondent 1, female, 11-15 years' service, full time FPU).

Others indicated that thoughts and images about specific cases could sometimes cause sleeping difficulties,

This was the case regarding the video recording of the child being abused which I had to view, especially as I had personally interview[ed] the child previously (Respondent 43, female, 4-7 years' service, full time FPU).

\section{Emotional Response to Work}

When asked to provide comments on whether they had experienced an altered emotional response to work, some participants did report experiencing an altered response both within and outside the work context. One participant reported,

I cried my eyes out frequently in the first week of my posting, at the end I was more hardened to the abuse suffered, you get used to such horrible work and hearing harrowing stories (Respondent 63, female, 16-20 years' service, Full time FPU).

Alternatively, other respondents talked about the professional dilemmas they experienced in relation to their emotional responses. One respondent said,

A recent historical sexual abuse enquiry involving two sisters abused by their father. From my time in the FACU the abuse was the most horrific and degrading that I have dealt with and being the first person both sisters had told in detail I felt a real sense of "wanting to get justice for them', while not showing my disgust of what they had been through. (Respondent 11, female, 11-15 year service, full time FPU) 
Table 2 Means, standard deviations, ranges and percentiles for intrusion, avoidance and arousal subscales and the full STSS

\begin{tabular}{|c|c|c|c|c|c|c|c|c|}
\hline & & & & Range & & & & Inferential statistics \\
\hline Scale & $\begin{array}{l}\text { Mean (SD) } \\
\text { total }\end{array}$ & $\begin{array}{l}\text { Mean (SD) } \\
\text { male }\end{array}$ & $\begin{array}{l}\text { Mean (SD) } \\
\text { female }\end{array}$ & Possible & $\begin{array}{l}\text { Observed } \\
\text { total }\end{array}$ & $\begin{array}{l}\text { Observed } \\
\text { male }\end{array}$ & $\begin{array}{l}\text { Observed } \\
\text { female }\end{array}$ & \\
\hline $\begin{array}{l}\text { Intrusion } \\
\text { subscale }\end{array}$ & $\begin{array}{l}7.73(2.81) \\
\alpha=.733\end{array}$ & $7.24(2.28)$ & $8.15(3.17)$ & $5-25$ & $5-14$ & $5-14$ & $5-14$ & $\begin{array}{c}U=440, z-.754, \mathrm{~ns}, \\
\quad r=-.01\end{array}$ \\
\hline $\begin{array}{r}\text { Avoidance } \\
\text { subscale }\end{array}$ & $\begin{array}{l}11.90(3.73) \\
\alpha=.696\end{array}$ & $11.79(2.96)$ & $12.00(4.33)$ & $7-35$ & $7-22$ & $7-17$ & $7-22$ & $\begin{array}{c}U=470, z-.320, \mathrm{~ns}, \\
\quad r=-.04\end{array}$ \\
\hline Arousal subscale & $\begin{array}{l}10.19(3.93) \\
\alpha=.763\end{array}$ & $9.76(3.23)$ & $10.56(4.47)$ & $5-25$ & $5-19$ & $5-16$ & $5-19$ & $\begin{array}{c}U=466, z-.375, \mathrm{~ns}, \\
\quad r=-.05\end{array}$ \\
\hline Full STSS & $\begin{array}{l}29.83(9.53) \\
\alpha=.882\end{array}$ & $\begin{array}{l}28.79(7.16) \\
\alpha=.763\end{array}$ & $\begin{array}{l}30.71(11.20) \\
\alpha=.923\end{array}$ & $17-85$ & $17-55$ & $18-43$ & $17-55$ & $\begin{array}{c}U=461, z-.442, \mathrm{~ns}, \\
\quad r=-.06\end{array}$ \\
\hline
\end{tabular}

\section{Empathy Shown to Complainers/Witnesses}

Many respondents reported an increase in their ability to empathise. One respondent said,

I understand the power of empathy and its usefulness as an investigatory aid. I would say working with the FACU (FPU) has increased my awareness and I now make more use of empathy' (Respondent 62, male, 2630 years' service, Supervisor).

Other respondents reported that they had developed an ability to detached their empathy,

I have gained the ability to be outwardly empathetic but detached (Respondent 11, female, 11-15 years' service, full time Female and Child Unit).

\section{Discussion}

This study provides data on STS amongst police officers conducting investigations in the FPU within the UK. It also aimed to explore the role of gender in the experience of STS as a result of the role they were performing and to establish types of symptoms they were experiencing. In total, half of the sample of respondents $(51 \%)$ were experiencing some degree of STS symptomatology with average scores of 29.83 on STSS.
For $40 \%$ of participants, symptoms were mild to moderate on the STSS, whilst for $11 \%$ of the participants, the degree of symptomatology was high or severe. Bride (2007) suggests a total score of over 38 on the STSS would be indicative of clinical levels of PTSD as a result of STS. Individuals in the high or severe categories were well over this score indicating that a reasonable proportion of FPU detectives may be experiencing clinical levels of STS.

These findings align with previous research in the USA exploring STS in law enforcement officials involved in online child exploitation cases who have also found that a large proportion of investigators report STS symptoms (Bourke and Craun 2014a; Brady 2016; Perez et al. 2010). For example, Bourke and Craun (2014a) found that over $70 \%$ of investigators had some symptoms of STS with a quarter of investigators reporting symptom levels that were high or severe. Perez et al. (2010) found that $18 \%$ of investigators were experiencing symptom levels that were high with an average score on the STSS at 36.11. Both of these studies report levels of symptoms that are even higher than those reported in this study. However, our findings were more in alignment with Craun et al. (2014) where $11.8 \%$ of law enforcement personnel experienced high or severe symptoms. Their sample of law enforcement personnel was broader than personnel just involved in child exploitation cases. Additionally, the findings of this study have some parallels with other contexts such as social work where Bride et al. 2004 found that average scores on the STSS were 29.5. It would be interesting to further explore whether specific types of investigations leave individuals
Table 3 Frequency and level of secondary traumatic stress experience by police investigating child protection

\begin{tabular}{llllc}
\hline $\begin{array}{l}\text { Category } \\
\text { (based on percentile) }\end{array}$ & $\begin{array}{l}\text { Level of secondary } \\
\text { traumatic stress }\end{array}$ & Total $N(\%)$ & Male $N(\%)$ & Female $N(\%)$ \\
\hline 50 th-less than 29 & Little or no & $32(51)$ & $16(25)$ & $16(25)$ \\
75 th-between 29 and 34 & Mild & $14(22)$ & $7(11)$ & $7(11)$ \\
90 th-between 35 and 42 & Moderate & $10(16)$ & $5(8)$ & $5(8)$ \\
95 th-between 43 and 49 & High & $3(5)$ & $1(2)$ & $2(3)$ \\
Above 95th-50+ & Severe & $4(6)$ & $0(0)$ & $4(6)$ \\
\hline
\end{tabular}


more at risk to symptoms of STS. Brady (2016) found evidence to suggest that the type of content of materials that individuals were investigating related to risk of STS. Furthermore, Perez et al. (2010) found that the amount of time individuals had exposure to disturbing material correlated with STS symptoms. Additionally, the vast majority of cases exploring STS in law enforcement personnel have been conducted in the USA. The only study that reports on STS in law enforcement personnel in the UK found that rates of STS were lower in the UK as compared to the USA (Bourke and Craun 2014b). Our findings also support the idea that reported symptoms of STS in police officers in the UK may be lower than those reported in the USA. It would be important to further explore why these differences might exist.

When exploring the subscale scores on the STSS (sub divided into intrusion, avoidance and arousal symptoms), certain symptoms within some of the scales were more frequently reported amongst the group. Within the intrusion subscale, just over a third of the respondents $(n=22)$ indicated that they thought about their work without intending to. Given the nature of the work and the intimate details respondents frequently had to listen and note statements about, it was not surprising that individuals were experiencing intrusions. When exploring literature around PTSD, experiencing intrusions is not necessarily indicative of whether or not someone continues to experience distress and PTSD symptoms in the future (Michael et al. 2005). It is the way in which individuals appraise the intrusion, specifically if they have dysfunctional negative beliefs about it (e.g. 'repeatedly thinking about this event means that there is something wrong with me') that seems to be pivotal in the maintenance of the symptom and this may also relate to other symptoms such as avoidance (Ehlers and Steil 1995). Therefore, further work could explore the nature of such intrusions and the way in which individuals are appraising them.

As far as the arousal subscale, hyper vigilance was the second most endorsed statement, followed by difficulty concentrating, irritability and difficulty sleeping. Furthermore, when examining avoidance symptoms, emotional numbing, detachment from others and diminished activity levels and inability to recall client information were the symptoms most frequently reported. Avoidance behaviours can be linked to a helpful concept within the clinical literature called safety behaviours where individuals engage in both cognitive and behavioural avoidance strategies to reduce anxiety (Moulds et al. 2008). Paradoxically, literature suggests that engaging in these safety behaviours contributes to disorder maintenance (Salkovskis 1989). Other studies exploring coping in relation to STS have found that coping through denial is related to higher STS scores (Bourke and Craun 2014a; Bourke and Craun 2014b; Craun et al. 2014). It is also important to explore how cultural norms within the police might interact with issues like avoidance behaviours. Anecdotally, police personnel have shied away from admitting that certain incidents were upsetting, with the perpetuating stance being that people knew what they were getting into when they joined the police and being expected to show a 'stiff upper lip' (Pryce et al. 2007). Pryce et al. (2007) assert that when supervisors and colleagues inform co-workers that they 'just have to get used to it all' (pp. 82) and subsequently avoid discussions about cases and any associated effects of trauma on workers, it shows 'maladaptive coping' behaviour on the part of the supervisor. In future studies, it would be important to further explore how cultural norms may influence coping of DOs.

No significant differences were found between men and women in relation to scores on the overarching STS scores or the subscales. This is in alignment with research in STS and PTSD that reports that gender is not predictive of symptomatology (Andrew et al. 2008; Craun et al. 2014; Ellrich and Baier 2015; Pole et al. 2001). However, other studies have reported that being male is associated with lower risk for STS and PTSD (Bourke and Craun 2014a; Bowler et al. 2010; Brady 2016) which aligns with the broader literature exploring PTSD in the general population (Tolin and Foa 2006). Finally, Bourke and Craun (2014b) found that being male was associated with lower STS scores only in their US sample and not their UK sample. This suggests that exploring the influence of gender across context such as the US A and UK might be important.

The questionnaires also explored certain symptoms in more detail collecting both quantitative and qualitative data. The study provided further support for the idea that a large proportion of FPU detectives are experiencing burnout, sleeping difficulties, altered emotional responses to work and changes in empathy towards complainers/witness. The qualitative data provides more in depth descriptions of what the experiences of these symptoms or cognitive and behavioural changes are like.

It is important to note that not all of the changes reported by the broader participant group were negative. Over half of the respondents indicated that they were now more empathetic towards the people they came into contact with and had developed skills such as being able to appear empathetic yet maintain a level of detachment from a situation. This aligns with other literature that suggests that there can be positive symptoms associated with doing this type of work (Perez et al. 2010; Stamm 2002). For instance, both Perez et al. (2010) and Stamm (2002) found that instead of being negatively affected by the work, many individuals feel great satisfaction that they have made some sort of difference. This may act as a buffer and be protective from negative feelings, reactions and experiences. Furthermore, there may be opportunities to further explore this area and what is means considering other theoretical frameworks. For instance, communication accommodation theory may be helpful in exploring the ways in which Detective Officers learn to accommodate their communication to more successful function in these contexts (Giles and Ogay 2007). It would be important to continue to explore both the positive and negative aspects to understand the full complexity of how engaging in this type of work links with STS. 


\section{Methodological Strengths and Limitations}

Due to the specific nature of the study and the area of specialism being explored (only Detective Officers working in the FPU), the study does not provide a view of STS across the broader police force. In any subsequent studies, a larger sample consisting of child protection Detective Officers from across the Police Force would be desirable. This would also provide opportunity for further more complex statistical analyses. A further limitation in the study is that participants self-selected to participate in the study by deciding to return the questionnaires. A total of 100 questionnaires were originally disseminated with 63 being returned. The views of any person, who failed to take part or return questionnaires, have not been represented in the results of the study and as such may cause a further bias to the results. Relatedly, the data are self-reported and therefore the limitations that arise in self-reported data must be considered. For instance, it is also important to note that respondents were asked to report whether they were working with people who had experienced trauma. It is recognised that individual understanding of 'trauma' may vary quite considerably and such understanding may be at variance with clinical definitions as well individual's own interpretation over time.

The STS scale should also be considered. Having researched thoroughly the assessment tools/instruments that are frequently used to assess whether people are experiencing the various stress-related constructs, Bride et al.'s (2004) STS Scale was deemed the most suitable for the study to capture data in connection with the study's aims. Sabo (2006) argues that although Bride's STS Scale provides a fast and simple assessment tool to gauge the presence of STS, as with many of the trauma instruments, the target population is a specific group of health care professionals and/or social workers, which she suggests indicates a 'lack of adaptability to accommodate a variety of STS exposures' (pp. 139). Discussions with the instrument's author, Brian Bride, identified that the STS Scale was considered the instrument that could be used to ascertain if police officers were experiencing STS. Given the similarities in post and the ability of the researcher to alter certain words in Bride's instrument to suit the group of persons being surveyed without affecting the instrument, out of all the assessment instruments/tools, it was considered the most appropriate for this study.

\section{Implications for Professionals and Policy Makers}

There is growing empirical evidence of the existence of STS and the effects of the phenomenon on the professionals who work with people who are traumatised. The current study suggests that Detective Officers conducting child protection enquiries are no less immune to the effects of STS than their counterparts in health or social work services. The results raise a number of questions about current practice, policy, procedures and the services provided to staff conducting child protection investigations. The officers in this study were provided with support resources they could engage with such as incident stress debriefing and confidential advice and counselling services through the Employee Well-being Programme. However, these resources were only available through selfreferral mechanisms. Officers were also provided with a 3week training course which provided training in General CID investigation duties covering, murder, serious crime investigation, fire investigation, serious assault, rape, sexual offences, cells site analysis of mobile phone enquiries and taperecorded interview training. Officers also could attend bespoke training courses (e.g. Domestic Abuse Training courses, Child Protection Training courses, Sexual Assault Investigation course). Although beyond the scope of this paper, it would be important to explore the efficacy of such resources, particularly the self-referral resources, and whether there is scope for developing this support further. Through the identification of key barriers and facilitators, there may be opportunity to enhance the existing support systems. For example, the findings from this study and future studies on STS could form the foundation on which to inform and build future police child protection education and learning, supervisory support, practices and policy.

It might also be important to explore whether certain individuals might be more vulnerable to STS because of previous history, having children or dependents, age, experience or length of exposure. For instance, there is evidence from the literature that prior childhood trauma is associated with a greater likelihood of adverse reaction when providing services to sexual abuse survivors (Follette et al. 1994). These groups may have special support or training needs that could be identified and developed. Police Forces need to ensure that staff within the FPU are appropriately supported and de-briefed in a bid to minimise/reduce the potential risk of psychiatric harm incurred by Forces failing to take 'adequate precautions' to reduce such risks. Other studies have highlighted the importance of support of co-workers, supervisors and the organisation in mitigating symptoms of STS (Bourke and Craun 2014a; Bourke and Craun 2014b; Brady 2016; Craun et al. 2014). Additionally, social support outside of work has also been reported as a mitigating factor (Bourke and Craun 2014a; Brady 2016; Perez et al. 2010).

In light of incidents such as an Officer being paid damages for psychiatric harm in Australia (New South Wales v. Seedsman, 2000), it is important to consider the role the UK police plays in supporting officers impacted by STS. Is it still legitimate for UK Police Forces to rely on Alcock v. Chief Constable of South Yorkshire Police (1992) decision that perpetuates the British courts' unwillingness to recognise the effects of secondary exposure to traumatic incidents/events and the effects on police officers because of its emphasis on 'promixity in time and space' to an incident or the existence of a 'close tie of love and affection with the victim' (Brown and 
Porteous 2003, pp. 566)? Such decisions minimise the fear of the floodgates opening and thus serving to narrow the range and reduce the number of actions brought against Chief Officers by potential secondary victims. As mentioned earlier, it is important for Forces to address the well-being of personnel, to deal effectively with work-related stressors, to ensure the effectiveness of operations and competency of Police Forces. A new document, Policing Vision 2025, aligns with this view where there is a focus on 'building an evidence base on staff well-being [.. .] so that those who work in policing can be supported and valued through change' (National Police Chiefs' Council, 2016, pp. 9). The ultimate aim being to enhance the performance of the organisation and provide better service to the public. It is important to look at preventative measures particularly for trainees new to this type of work but also intervention strategies for individuals experiencing high levels of STS symptoms. In addition to health costs for individuals, there are implications for the broader functioning of the department when a proportion of individuals are experiencing clinical levels of STS. Therefore, these strategies must move beyond focusing just on individuals but also exploring strategies at a collective level (it is important to note here that the department was informed of the STS levels of staff whilst protecting the identity of individuals).

\section{Implications for Future Research}

A number of areas were touched upon in this study, but would merit further time and research. The study has raised questions about what is it about child protection work that impacts on the ability of the individuals performing this role to persevere even at times of intense pressure and heavy workloads. Furthermore, it would be important to explore the impact of this work longitudinally. Relatedly, it would be important to explore these impacts on individuals who are more junior. For instance, work in other sectors such as medicine suggest that having more clinical experience may be a protective factor against distress when facing traumatic events (Jackson et al. 2005). This suggests that trainees may be a particularly vulnerable group that need targeted support. This finding aligns with other work which has found differences in reactions by number of years of exposure and seniority of role (Brown and Blount, 1999). Furthermore, the literature suggests that exposure to specific types of incidents and the amount of time individuals are exposed to these incidents enhances vulnerability to STS (Brady 2016; Perez et al. 2010). It would be important to further disentangle these issues to better target support for individuals working in these contexts. Finally, through longitudinal work, it may be possible to learn more about how experience changes STS or distress more generally. Some of the data suggests this type of work also creates opportunity for positive growth for individuals. It would be of value to explore factors that promote and support growth and resilience.
This also raises further questions over supervision and support and the significance of child protection work in the police force priorities. Although high on the UK Government and police force priorities and control strategy, respondents still perceive their work to be less important and minimised in the 'bigger picture' of policing priorities, with lack of staff, under funding and working conditions exacerbating the situation. To what extent are such perceptions linked to managers and senior officers not having had first-hand experience of being a practitioner within FPUs? Are there any underlying reasons precluding FPU practitioners from being readily identified for promotion and placed in supervisory roles within the department, where their knowledge and experience may influence practice and quality of supervision to practitioners? Therefore, this area too warrants research into any causal factors affecting promotion of female FPU officers. The absence of research in Police FPUs remains, with a crucial need for research in this occupational group of police officers. Finally, further empirical studies are required to be undertaken on the effects of STS on police officers who conduct child protection enquiries, both from a national and international perspective.

\section{Compliance with Ethical Standards}

Conflict of Interest The authors declare that they have no conflict of interest.

Ethical Approval University of Dundee Research Ethics Committee and the organisation where this study was conducted approved the study.

Informed Consent Participants were provided with information sheet and consent form. Informed consent was obtained from all participants. Due to the sensitive nature of the study, information and contact details of relevant occupational health service were also provided.

Open Access This article is distributed under the terms of the Creative Commons Attribution 4.0 International License (http:// creativecommons.org/licenses/by/4.0/), which permits unrestricted use, distribution, and reproduction in any medium, provided you give appropriate credit to the original author(s) and the source, provide a link to the Creative Commons license, and indicate if changes were made.

\section{References}

Alcock v. Chief Constable of South Yorkshire Police. (1992)

Alexander DA, Wells A (1991) Reactions of police officers to bodyhandling after a major disaster. Br J Psychiatry 159:547-555

Andrew ME, McCanlies EC, Burchfiel CM, Charles LE, Hartley TA, Fekedulegn D, Violanti JM (2008) Hardiness and psychological distress in a cohort of police officers. Int J Emerg Mental Health 10:137-148

American Psychiatric Association (APA) (2000) Diagnostic and statistical manual of mental disorders, 4th edn. American Psychiatric Association, Washington, DC

Bride, B., Robinson, M., Yegidis, B., \& Figley, C. (2004). Development and Validation of the Secondary Traumatic Stress Scale. Research on Social Work Practice, 14(1), 27-35. 
Bourke ML, Craun SW (2014a) Secondary traumatic stress among internet crimes against children task force personnel: impact, risk factors, and coping strategies. Sex Abus 26(6):586-609

Bourke ML, Craun SW (2014b) Coping with secondary traumatic stress: difference between U.K. and the U.S. child exploitation personnel. Traumatology: An Int J 20(1):57-64

Bowler RM, Han H, Gocheva V, Nakagawa S, Alper H, DiGrande L, Cone JE (2010) Gender differences in probable posttraumatic stress disorder among police responders to the 2001 World Trade Center terrorist attack. Am J Ind Med 53(12):1186-1196

Brady PQ (2016) Crimes against caring: exploring the risk of secondary traumatic stress, burnout, and compassion satisfaction among child exploitation investigators. J Police Crim Psychol 1-14

Bride B, Robinson M, Yegidis B, Figley C (2004) The development and validation of the secondary traumatic stress scale. Res Soc Work Pract 14(1):27-35

Bride B (2007) Prevalence of secondary traumatic stress amongst social workers. Soc Work 52(1):63-70

Bride B, Kintzle S (2011) Secondary traumatic stress, job satisfaction, and occupational commitment in substance abuse counselors. Traumatology 17(1):22-28

Brown J, Blount C (1999) Occupational stress among sex offender treatment managers. J Manag Psychol 14(2):108-120

Brown J, Fielding J, Grover J (2010) Distinguishing traumatic, vicarious, and routine operational stressor exposure and attendant adverse consequences in a sample of police officers. Work Stress: Int J Work Health Organ 13(4):312-325

Brown J, \& Porteous J (2003) Psychological and legal implications of occupational stress for criminal justice practitioners. In Carson D \& Bull R (ed) Psychology in legal context p 559-577

Collins S, Long A (2003) Working with the psychological effects of trauma: consequences for mental health-care worker - a literature review. J Psychiatr Ment Health Nurs 10:417-424

Craun SW, Bourke ML, Bierie DM, Williams KS (2014) A longitudinal examination of secondary traumatic stress among law enforcement. Victims Offenders 9(3):299-316

Denscombe M (2007) The good research guide for small-scale social research projects. Open University Press, Maidenhead

Ehlers A, Steil R (1995) Maintenance of intrusive memories in posttraumatic stress disorder: a cognitive approach. Behav Cogn Psychother 23:217-249

Ellrich K, Baier D (2015) Post-traumatic stress symptoms in police officers following violent assaults. J Interpers Violence 32(3):331-356

Figley C (1995) Compassion fatigue: coping with secondary traumatic stress disorder in those who treat the traumatised. Brunner/Mazel, New York

Follette VM, Polusny MM, Milbeck K (1994) Mental health and law enforcement professionals: trauma history, psychological symptoms, and impact of providing services to child sexual abuse survivors. Prof Psychol : Res Pract 25(3):275-282. https://doi.org/10. 1037/0735-7028.25.3.275

Giles, H., \& Ogay, T. (2007). Communication Accomodation theory. In B.B. Whaley \& Samter (Eds.), Explaining communication: contemporary theories and exemplars (pp. 293-310). Lawrence Erlbaum, Mahwah, NJ

Herman J (1992) Trauma and recovery. Basic Books, New York

Hodgins GA, Creamer M, Bell R (2001) Risk factors for posttrauma reactions in police officers: a longitudinal study. J Nerv Ment Dis 189(8):541-547

Jackson VA, Sullivan AM, Gadmer NM, Seltzer D, Mitchell AM, Lakoma MD et al (2005) "It was haunting...": physicians' descriptions of emotionally powerful patient deaths. Acad Med 80(7):648-656

Jenkins SR, Baird S (2002) Secondary traumatic stress and vicarious trauma: a validation study. J Trauma Stress 15:423-432

Joinson C (1992) Coping with compassion fatigue. Nursing 22(4):116-120
Leinwber J, Rowe HJ (2008) The costs of 'being with woman': secondary traumatic stress in midwifery. Midwifery 26(1):76-87

Levin AP, Kleinman SB, Adler JS (2014) DSM-5 and postraumatic stress disorder. J Am Acad Psychiatry Law 42(2):146-158

Lilly MM, Pole N, Best SR, Metzler T, Marmar CR (2009) Gender and PTSD: what can we learn from female police officers? J Anxiety Disord 23(6):767-774

MacEachern AD, Jindal-Snape D, Jackson S (2011) Child Abuse Investigation: Police Officers and Secondary Traumatic Stress. Int J Occup Saf Ergon 17(4):329-339

Martin CA, McKean HE, Velktramp LJ (1986) Post traumatic stress disorder in police working with victims: a pilot study. J Police Sci Adm 14:98-101

McCann I, Pearlman L (1990) Vicarious traumatisation: a framework for understanding the psychological effects of working with victims. J Trauma Stress 3(2):131-149

Michael T, Ehlers A, Halligan SL, Clark DM (2005) Unwanted memories of assault: what intrusion characteristics are associated with PTSD? Behav Res Ther 43(5):613-628

Moulds ML, Kandris E, Williams AD, Lang T, Yap C, Hoffmeister K (2008) An investigation of the relationship between cognitive reactivity and rumination. Behav Ther 39(1):65-71

Munroe JF, Shay J, Fisher L, Makary C, Rapperport K, \& Zimering R (1995) Preventing compassion fatigue: a team treatment model. In: Figley CR (ed) Compassion fatigue: coping with secondary traumatic stress disorder in those who treat the traumatized p 209-231

Najjar N, Davis LW, Beck-Coon K, Carney Doebbeling C (2009) Compassion fatigue: a review of the research to date and relevance to cancer-care providers. J Health Psychol 14(2):267-277

National Police Chiefs' Council (2016) Policing vision 2025. National Police Chiefs' Council. Accessed 12/26/17: http://www.npcc.police. uk/documents/Policing\%20Vision.pdf New South Wales v. Seedsman. (2000)

Palm KM, Polusny MD, Follette VM (2004) Vicarious traumatization: potential hazards for disaster and trauma workers. Prehosp Disaster Med 19(1):73-78

Perez LM, Jones J, Englert DR, Sachau D (2010) Secondary traumatic stress and burnout among law enforcement investigators exposed to disturbing media images. J Police Crim Psychol 25(2):113-124

Pole N, Best SR, Weiss DS, Metzler T, Liberman AM, Fagan J, Marmar CR (2001) Effects of gender and ethnicity on duty-related posttraumatic stress symptoms among urban police officers. J Nerv Ment Dis 189(7):442-448

Pryce J, Shackelford K, Pryce D (2007) Secondary traumatic stress and the child welfare professional. Lyceum Books Inc, Chicago, Illinois

Sabo BM (2006) Compassion fatigue and nursing work: can we accurately capture the consequences of caring work. Int J Nurs Pract 12:136-142

Salkovskis PM (1989) Cognitive-behavioural factors and the persistence of intrusive thought in obsessional problems. Behav Res Ther 27: $677-682$

Sewell JD (1994) The stress of homicide investigations. Death Stud 18: $565-582$

Stamm BH (2002) Measuring compassion satisfaction as well as fatigue: developmental history of the compassion satisfaction and fatigue test. In: Figley CR (ed) Treating compassion fatigue. BrunnerRoutledge, New York, pp 107-119

State of New South Wales v Seedsman (2000). NSWCA 119, 12 May 2000 (BC 200002477).

Sugimoto JD, Oltjenbruns KA (2001) The environment of death and its influence on police officers in the United States. Omega: J Death Dying 43(2): 145-155

Tolin DF, Foa EB (2006) Sex differences in trauma and posttraumatic stress disorder: a quantitative review of 25 years of research. Psychol Bull 132(6):959-992 